The isoelectric point of proteins influences their translocation to the extrahaustorial matrix of the barley powdery mildew fungus

Smigielski, Lara; Aguilar, Geziel B.; Kwaaitaal, Mark; Zhang, WenJing; ThordalChristensen, Hans

Published in:

Cellular Microbiology

DOI:

$10.1111 / \mathrm{cmi} .13091$

Publication date:

2019

Document version

Early version, also known as pre-print

Citation for published version (APA):

Smigielski, L., Aguilar, G. B., Kwaaitaal, M., Zhang, WJ., \& ThordalChristensen, H. (2019). The isoelectric point of proteins influences their translocation to the extrahaustorial matrix of the barley powdery mildew fungus.

Cellular Microbiology, 21(12), [e13091]. https://doi.org/10.1111/cmi.13091 
University of Copenhagen, August 6, 2019.

This is the pre-peer reviewed version of the following article:

"The isoelectric point of proteins influences their translocation to the extrahaustorial matrix of the barley powdery mildew fungus",

which has been published in final form in

Cellular Microbiology at https://doi.org/10.1111/cmi.13091.

This article may be used for non-commercial purposes in accordance with Wiley Terms and Conditions for Use of Self-Archived Versions. 


\title{
The isoelectric point of proteins influences their translocation to the extrahaustorial matrix of the barley powdery mildew fungus
}

\author{
Lara Smigielski ${ }^{1}$, Geziel B. Aguilar ${ }^{1}$, Mark Kwaaitaal ${ }^{1,2}$, Wen-Jing Zhang $^{1}$ and Hans \\ Thordal-Christensen ${ }^{1}$ \\ ${ }^{1}$ Department of Plant and Environmental Sciences, Copenhagen Plant Science Centre, University of \\ Copenhagen, DK-1871 Frederiksberg C, Denmark \\ ${ }^{2}$ Present address: Swammerdam Institute for Life Sciences, University of Amsterdam, The Netherlands
}

\section{Correspondence}

Hans Thordal-Christensen, Department of Plant and Environmental Sciences, Copenhagen Plant Science Centre, University of Copenhagen, DK-1871 Frederiksberg C, Denmark.

E-mail: htc@plen.ku.dk

\section{ABSTRACT}

Many biotrophic fungal plant pathogens develop feeding structures, haustoria, inside living plant cells, which is essential for their success. Extrahaustorial membranes (EHMs) surround haustoria and delimit the extrahaustorial matrices (EHMxs). Little is known about transport mechanisms across EHMs and what properties proteins and nutrients need in order to cross these membranes. To investigate this further, we expressed fluorescent proteins in the cytosol of infected barley leaf epidermal cells after particle bombardment and investigated properties that influenced their localization in the powdery mildew EHMx. We showed that this translocation is favoured by a neutral isoelectric point (pl) between 6.0 and 8.4. However, for proteins larger than $50 \mathrm{kDa}$, pl alone does not explain their localization, hinting towards a more complex interplay between $\mathrm{pl}$, size and sequence properties. We discuss the possibility that an EHM translocon is involved in protein uptake into the EHMx. 


\section{KEYWORDS}

Powdery mildew fungus, extrahaustorial membrane, extrahaustorial matrix, protein translocation

\section{INTRODUCTION}

Specialization and adaptation ensure survival in nature. In some cases, the specialization and adaptation of a pathogen to a specific plant niche is so high that living without it is no longer possible. This so-called obligate biotrophic interaction is true for the powdery mildew fungus, Blumeria graminis f. sp. hordei (Bgh), which colonizes barley (Hordeum vulgare) and can give a yield loss of $10-20 \%$ (https://www.cabi.org/isc/datasheet/22075). In order to survive, the fungus establishes an intimate symbiosis with the host plant, involving bidirectional transport across membranes allowing communication, manipulation and delivery of molecules. After successful penetration, a fungal feeding structure, the haustorium, is formed inside the host cell. This differentiated hypha becomes surrounded by a host-generated extrahaustorial membrane (EHM) that possesses endoplasmic reticulum (ER) membrane-like properties (Kwaaitaal et al. 2017). Between the haustorium and the EHM, a compartment called the extrahaustorial matrix (EHMx) is located. In contrast to the membranes and organelles in very close proximity to the EHM on the side of the host (Kwaaitaal et al 2017), transmission electron micrographs have shown the EHMx to be easily discernible and up to $3 \mu \mathrm{m}$ wide (Hippe-Sanwald et al., 1992). Interestingly, the chloroplast protein, PSI-D, was localized in haustoria of Erysiphe pisi growing on pea, thus suggesting protein transport across both the EHM and the fungal plasma membrane (Testut, Callow, \& Green, 1999). Otherwise, molecular and cellular information available on the haustorial complex is very sparse, despite the obvious importance of this compartment. Therefore, any novel information about it will be very useful as it forms the basis for further studies that eventually could lead to design of disease resistance.

In order to manipulate plant immunity, effector molecules are likely to be transported from the fungus to the plant cell (Lu et al., 2016). The Bgh genome encodes 
approximately 500 so-called candidate secreted effector proteins (CSEPs) (Pedersen et al., 2012), for some of which there is evidence that they contribute positively to the success of the fungus (e.g. Aguilar et al. 2016; Ahmed et al. 2015; Pennington et al. 2016).

The present study was initially meant to analyse the subcellular localization of CSEPs in barley leaf epidermal cells. Serendipitously, however, our observations instead confirmed our previous finding (Ahmed et al., 2015) that proteins often are translocated from the host cytosol, across the EHM, into the EHMx. Being an entirely unstudied phenomenon, we looked further into it and found interesting details on protein properties influencing uptake into the EHMx. We found that neutral $\mathrm{pl}$ is an essential property for proteins to accumulate in the EHMx. However, protein size and sequence also influence uptake.

\section{RESULTS}

\section{Extrahaustorial matrix localization of proteins expressed in the plant cytosol is influenced by their pl}

We have previously observed that free monomeric $(\mathrm{m})$ Cherry, free monomeric Yellow Fluorescent Protein (mYFP) and mYFP-CSEP0162 (without signal peptide for secretion), expressed in the cytosol of barley epidermal cells with Bgh haustoria, were not only present in the plant cell cytosol, but strikingly also entered the EHMx (Ahmed et al., 2015). This compartment is distinct in bright field images obtained by confocal microscopy (Figure 1, Supplemental Figure 1). mCherry is clearly present in the EHMx between the EHM, labelled by GFP-HvRabD2a previously shown to bind to this membrane (Mark Kwaaitaal et al., 2017), and the haustorium (Figure 1). The signal of free mCherry in a region of interest (1) (ROI (1)) in the EHMx, relative to the one in a ROI (2) in the plant cytosol, is 2.51 (mean of 106 cells; SE, 0.148 ). When expressing free mYFP in the plant cytosol, ROI1/ROI2 equals 2.86 (mean of 53 cells; $\mathrm{SE}$, 0.218). While this indicated that intact proteins are able to cross the EHM, our previous study also demonstrated that certain proteins did not localize to the EHMx, as found for mYFPCSEP0105 (Ahmed et al., 2015). Here we expanded the analysis, and examined mYFP fusions of $11 \mathrm{Bgh}$ CSEPs without signal peptides, thus forcing their targeting to the cytosol. This allowed localization analysis of proteins with diverse sequence, $\mathrm{pl}$ and size in barley epidermal cells with Bgh haustoria 48 hours post inoculation (hpi). The CSEPs were fused to either the 
$\mathrm{N}$ - or C-terminus of mYFP. However, independent of the orientation of the fusion, seven of the CSEP fusions were visible in the EHMx and four were not (Figure 2. and Table 1).

We considered if protein size could determine whether they localize to the matrix or not. However, we initially declined this idea as the largest fusion proteins (up to $74 \mathrm{kDa}$ ) generally localized to the EHMx, while some of the smallest (down to $41 \mathrm{kDa}$ ) generally did not (Table 1). Instead, we turned to examine the protein's calculated pl-values. Here we noted that the CSEP-fusions that entered the EHMx have a predicted $\mathrm{pl} \geq 6.0$, and those that did not, have a predicted $\mathrm{pl} \leq 5.8$, with the exception of CSEP0162 ( $\mathrm{pl} 5.6$ ), which did localize to the EHMx (Table 1). To test the causality behind this correlation, we generated a series of constructs encoding pl-modified mCherry, with varying numbers of aspartates (Asp), lysines (Lys) and alanines (Ala) added to its C-terminus (Table 2). After co-expressing those plmodified mCherry versions with mYFP ( $p \mid 6.2$ ) in barley leaf epidermal cells with Bgh haustoria, we quantified their accumulation in the EHMx. Here the mCherry signal at a ROI (1) in the matrix, normalized to the signal of mYFP in the same ROI, was recorded relative to the mCherry signal at a ROI (2) in the plant cytosol as well normalized to the mYFP signal (Figure 3). The results indeed suggested an effect of pl on protein localization in the matrix. The quantifications demonstrated that proteins with $\mathrm{pl}$ values between 6.0 and 8.4 were efficiently translocated from the plant cell cytosol to the matrix, while this feature was gradually lost when proteins possessed more extreme pls.

To confirm these observations, we reversed the fluorescent proteins and generated constructs encoding pl-modifed mYFP (Table 2), which we co-expressed with mCherry (pl 5.9) for normalization. The data obtained with these constructs corroborated the data from the pl-modified mCherry (Figure 3b). As mCherry and mYFP have low amino acid identity (29\%), our data suggested that the modified pl due to the added aspartates and lysines at the Cterminus determined localization of these proteins in the EHMx.

As our initial non-quantitative examination suggested that high pl CSEP-mYFP fusion proteins readily localized to the EHMx, unlike the high pl mCherry and mYFP, we re-tested seven mYFP-CSEPs and quantified their distribution between the cytosol and EHMx. The data are included in Figure $3 \mathrm{~b}$ and align well with the mCherry and mYFP-data (with the exceptions of CSEP0422, pl 5.8, and CSEP0244, pl 8.7), again validating that efficient EHMx targeting depends on the $\mathrm{pl}$. In this case, except for mCherry or mYFP no amino acids were artificially 
attached to the $\mathrm{C}$ - or $\mathrm{N}$-terminus, suggesting that EHMx recruitment depends on the overall protein $\mathrm{pl}$ and not our modifications.

\section{Protein size, sequence and pl affect translocation to the extrahaustorial matrix}

We found that pHusion, a pH sensor with a size of $52 \mathrm{kDa}$ was targeted poorly to the EHMx, even after we increased its $\mathrm{pl}$ to 6.2 or 6.5 , which according to our findings with modified mCherry and mYFP proteins would facilitate take-up into the EHMx. In this case, the quantification was done with without normalization since pHusion is a GFP-RFP fusion protein (Gjetting, Ytting, Schulz, \& Fuglsang, 2012), leaving little option for use of a fluorescent reference protein (Table 3). A CFP-YFP fusion protein having a similar size was tested to confirm this observation, and here mCherry could be used as reference protein. Also, in this case, a very low signal was detected in the EHMx even though the pl of 6 was predicted to permit EHMx targeting (Table 3). In summary, the matrix uptake of the double-fluorescent proteins ( $\sim 52 \mathrm{kDa})$ was only $10-20 \%$ of that of single fluorescent proteins ( $27 \mathrm{kDa})$, suggesting that also protein size influences translocation into the EHMx.

Despite the reduced EHMx localization of double-fluorescent proteins, we observed that larger CSEP-mYFP fusion proteins with a size above $70 \mathrm{kDa}$ were taken up into the EHMx. Additionally, as indicated above, CSEP0422-mYFP had a low relative intensity in the matrix even though it has a low molecular weight ( $41 \mathrm{kDa}$ ) and a pl of 5.8 (Figure $3 \mathrm{~b})$. This shows that not only $\mathrm{pl}$ and size influence the translocation into the EHMx, but also the amino acid sequence and how this may affect protein structure of the translocated protein seems to be important.

\section{Extreme pl hardly drives fungal effectors across the extrahaustorial membrane into the host cytosol}

We know little on the directionality of the protein transfer across the EHM, as we have only made snap shots at single time-points and no studies of the transfer dynamics were possible. Yet, protein transfer may be bi-directional, and what we observe are equilibria of proteins moving in and out of the matrix. At the same time, it is unclear how effector proteins, secreted 
by the fungal haustoria into the matrix, make their way to the host cytosol. If matrix chemical or physical conditions are important for the pl-influenced EHMx localization, it could be that effectors with extreme pls are driven to the host cytosol as a result of a pl-dependent exclusion from the EHMx.

To investigate this possibility, we profiled the predicted pl-values of 491 CSEPs (Pedersen et al., 2012). The resulting multimodal pl-profile indeed suggested that most effector candidates ( $\approx 60 \%$ ) have pl-values outside the 6.0-8.4 interval (Figure S2a) that permits EHMx accumulation of host cell-expressed proteins. This would suggest that the extreme pl-effectors are driven out of the matrix. However, data suggests that this effector candidate multimodal pl-profile is unbiased and not selected for, as pl-values of theoretical proteins generated to reflect the amino acid occurrence broadly found in eukaryotes, show an identical multimodal profile (Weiller, Caraux, \& Sylvester, 2004). If a pl-based transfer would be in play, selection of proteins with permissive pl-values would be expected to skew the profile away from the one of theoretical non-selected proteins, like it is the case for extremophiles (Weiller et al., 2004). Even if we restrict the analysis to the 96 CSEPs, that have a transcript expression level in the haustorium above the mean (Pedersen et al., 2012), we found no skewing of their pl profile either (Figure S2b). Therefore, we have no reason to suggest that effector pl may be important for their expected transfer to the host cytosol.

\section{Nuclear export signal does not alter translocation to the extrahaustorial matrix}

The modified mCherry and mYFP, that are efficiently localized to the EHMx, have stretches of lysines reminiscent of nuclear localization signals (NLS), which are rich in lysines and arginines (Freitas \& Cunha, 2009). Consequently, a translocation mechanism through the EHM similar to nuclear import arose as a possibility. To test this idea, we fused a nuclear export signal (NES), identified in Haasen et al. (1999) and adapted to monocot plants (Scott, 2013), to the C-terminus of mCherry and examined its signal intensities in the nucleus, the EHMx and the cytosol relative to co-expressed mYFP. The signal in the nucleus, but not in the EHMx, was strongly reduced (Figure 4, Figure S3). This showed that the NES functioned as expected in protein export from the nucleus; however, the high fluorescent signal in the EHMx makes it unlikely that it NES-mediated nuclear export plays a role in protein translocation across the EHM. Yet it cannot be excluded that a mechanism using an NLS-like signal mediates protein transport across the EHM. 


\section{Neutral pH of the EHMx}

The observation that extreme pl proteins have poor uptake in the EHMx, suggests that highly charged proteins cannot access this compartment. As the $\mathrm{pH}$ of the environment, together with the $\mathrm{pl}$, determines the overall charge of the protein, it is very relevant to know the $\mathrm{pH}$ inside the EHMx. Therefore, we expressed two pH sensors in barley epidermal cells with haustoria, namely pHusion (see above) and pHluorin (Gao, Knight, Trewavas, Sattelmacher, \& Plieth, 2004; Miesenböck, De Angelis, \& Rothman, 1998). The 490/510 emission ratio of pHluorin and GFP/RFP emission ratio of pHusion did not differ between the nucleus and the matrix, suggesting that the two compartments have a similar pH (Figure S4). Meanwhile, the $490 / 510$ emission ratio of pHluorin was significantly higher in the cytosol compared to the nucleus and the EHMx (mean of 15 measurements). This suggests that the $\mathrm{pH}$ in the matrix might be slightly higher than the cytosol. However, this was not observed when using the pHusion sensor. Even though the detection maximum of both $\mathrm{pH}$ sensors is determined to be pH 8 (Gao et al. 2004; Gjetting et al. 2012; Miesenböck et al. 1998), other factors in the EHMx environment might cause the differences between the two sensors. Technical limitations prevented us from obtaining a reliable $\mathrm{pH}$ calibration curve. Nevertheless, our data might suggest a peripherally higher $\mathrm{pH}$ in the matrix relative to the cytosol.

\section{DISCUSSION}

In this study, we clearly show that proteins produced in the plant cytosol can enter the EHMx, which is easily discernible at haustoria of the barley powdery mildew fungus. The haustorial complex is delimited by an extrahaustorial membrane, which shares features with the ER membrane (Kwaaitaal et al. 2017), and the present data indicate that this membrane has a translocation mechanism. We suggest that accumulation in the EHMx is affected by 1) protein pl. With the addition of amino acids, the predicted isoelectric point of mCherry and mYFP was altered and their localization within the plant cell was investigated. We show that medium pl proteins ( $\mathrm{pl}$ 6.0-8.4) are efficiently translocated to the EHMx, whereas low and high pl proteins $(p \mid<6.0$ and $p l>8.4)$ are gradually less abundant in the EHMx (Figure $3 b$ ). We also find that 
accumulation depends on 2) protein size, as a single mYFP protein gave a strong matrix signal whereas double-fluorescent proteins did not. Finally, 3) protein sequence plays an important role, as CSEP0422-mYFP localized poorly, despite its small size of $40 \mathrm{kDa}$, while the larger CSEP0247-mYFP, CSEP0244-mYFP and CSEP0025-mYFP of approximately $70 \mathrm{kDa}$ accumulated well within the EHMx.

We cannot completely exclude that the observed differences in fluorescence intensities may be caused by differential degradation of the tested proteins in the matrix, and indeed, addition of lysines may increase proteolysis resistance (Markert, Koditz, UlbrichHofmann, \& Arnold, 2003). However, the fact that the highest number of lysines (12) added to the fluorescent proteins reduced the matrix signal, and the fact that the mYFP single fluorescent protein gave a stronger matrix signal than the double-fluorescent proteins, suggest that a translocation mechanism is determining protein targeting to the EHMx.

Co-translational and post-translational translocation mechanisms exist for uptake of soluble proteins into plant cell organelles. These mechanisms are all based on translocon proteins. We will disregard ER co-translational translocation, as all proteins in this study lack signal peptides. Different mechanisms are responsible for post-translational translocation into the ER, mitochondria, chloroplasts and peroxisomes (Kunze \& Berger, 2015). However, since we do not observe our marker proteins in any of these compartments, we have no reason to believe that one of these mechanisms is used directly for translocation across the EHM. Besides, we have previously found that the ER translocon protein, Sec61 $\beta$, is absent from the EHM (Zhang, Hanisch, Kwaaitaal, Pedersen, \& Thordal-Christensen, 2013). This agrees with the fact that the unmodified, cytosolic mCherry and mYFP, which are easily taken up, lack exposed alpha-helix structures (Soleja, Manzoor, Khan, Ahmad, \& Mohsin, 2018), which are required for targeting into these compartments (Kunze et al. 2015). We consider that the fact that size, $\mathrm{pl}$ and sequence influenced the EHMx uptake and suggest that a gated protein translocon is involved. We also consider that proteins may be taken up as globular proteins, as mYFP and mCherry quickly fold into their globular structure after translation, and we doubt that cells with haustoria have a chaperone system dedicated to unfold proteins for this uptake purpose. Therefore, we speculate that an EHM translocon may be flexible like the peroxisome import machinery is suggested to be (Emmanouilidis, Gopalswamy, Passon, Wilmanns, \& Sattler, 2016; Kunze \& Berger, 2015). Additionally, a pore complex similar to the nuclear pore complex is not likely, as the nuclear export signal showed no effect on the localization within 
the matrix (Figure 4). Yet, we cannot exclude that a translocation mechanism similar to nuclear import, but without the nuclear export function, may exists. We have searched CSEP0247, CSEP0244 and CSEP0025 for consensus sequence tags potentially guiding these large and easily taken-up proteins to a translocon. However, our efforts using https://wolfpsort.hgc.jp/, http://www.cbs.dtu.dk/services/DeepLoc/ and http://localizer.csiro.au/ have been in vain. Therefore, we hope that future sequence break-down analyses of CSEP0247, CSEP0244 or CSEP0025 will help us to identify a consensus sequence determining the up-take and perhaps also translocon proteins.

It is not obvious why proteins with extreme pl were poorly localized to the EHMx. We attempted to estimate the $\mathrm{pH}$ in the EHMx and found that it may be marginally higher than the cytosol $\mathrm{pH}$, which does not provide an explanation for the pl-effect. However, extreme pl proteins have a strong net charge that, irrespective of it being positive or negative, may hamper passage through a translocon pore.

Regardless of the translocation mechanism, our results suggest that proteins with an isoelectric point close to physiological pH accumulate more effectively after translocation to the EHMx than charged ones. The question arises whether there is a biological relevance of the matrix localization of plant expressed proteins. As described above, it may not be relevant for transfer of effectors to the plant cytosol. However, it may play a role in fungal nutrient uptake, where host proteins can reach the haustorium. Here they may be degraded on the outside of the haustorium PM and taken up as amino acids or small peptides, or they may be endocytosed as more or less intact proteins.

All-in-all, we consider the present description of protein translocation into the EHMx to be a valuable contribution to the otherwise sparse insight available on the haustorial complex.

\section{EXPERIMENTAL PROCEDURES}

\section{Plant and fungal growth conditions}

For bombardments, the barley line Ingrid ror2, hypersusceptible due to its mutation in the syntaxin gene, ROR2 (Collins et al., 2003), was used. Plants were grown for 7 days with a 
photoperiod of $16 \mathrm{~h}(150 \mu \mathrm{Es}-1 \mathrm{~m}-2)$ and $20 / 15^{\circ} \mathrm{C}$ day/night. Blumeria graminis f. sp. hordei isolate B103 was propagated on barley P-10 plants in a cycle of one week.

\section{Cloning of constructs}

Ubiquitin-promoter driven DNA constructs encoding CSEP0105, CSEP0162 and CSEP0254 (without signal peptides) fused to the C-terminus of mYFP were generated previously (Ahmed et al., 2015). Similar constructs were generated here for CSEP0025, CSEP0062, CSEP0244, CSEP0247, CSEP0345, CSEP0420, CSEP0422 and CSEP0443 (Pedersen et al., 2012). However, in this case the fusions were on the N-terminus of mYFP. In short, the CSEP coding sequences were amplified, without their signal peptide coding sequences, via PCR from cDNA of plant material infected with $\mathrm{Bgh}$, and cloned into $\mathrm{pENTR/D-TOPO}{ }^{\circledR}$ vectors (Invitrogen). After validation, the inserts were transferred in frame to a destination vector via a Gateway LR reaction, thus fusing the encoded protein to the $\mathrm{N}$-terminus of mYFP. For constructs encoding fluorescent proteins with different pls, empty Gateway destination vectors (pUbi-mCherryGateway and pUbi-mYFP-Gateway) (Kwaaitaal et al. 2010) were used as template for initial PCR amplification, using Q5 high-fidelity polymerase (New England Biolabs). In order to alter the $\mathrm{pl}$ of the fluorescent proteins (mCherry, mYFP and pHusion), codons for selected amino acids were added to the reverse primers (Table S1). The PCR products were cloned into the entry vector, pENTRD-TOPO. The YC3.6 sequence was amplified from the pcDNA3 vector (Nagai, Yamada, Tominaga, Ichikawa, \& Miyawaki, 2004) using Gateway compatible primers (Table S1) by PCR, and using a Gateway BP reaction recombined into pDONR201. Followed by an LR reaction, the coding sequences were transferred into the destination vector, pUbiGateway-nos, containing a ubiquitin promoter and a NOS terminator. In the process of cloning, heat shock transformation of TOP10 competent cells was used. All clones obtained were validated by sequencing.

\section{Particle bombardment}

For transient expression of the fluorescent proteins, the Biolistic PDS-1000/He Particle Delivery System from Bio-Rad was used. Several modifications to the manufacturer's manual were carried out: for each bombardment, seven detached barley leaves of 7-day-old plants were used. The particle coating was performed using $7 \mu \mathrm{g}$ DNA for each construct together 
with $2.4 \mathrm{mg}$ gold, $1 \mu \mathrm{g} / \mu \mathrm{l}$ protamine (Sivamani, Delong, \& Qu, 2009) and $0.625 \mathrm{M} \mathrm{CaCl}_{2}$ (RascoGaunt, Riley, Barcelo, \& Lazzeri, 1999). For the bombardments, a hepta adapter and rupture discs bursting at a helium pressure of 1.100 psi were used. After bombardment, the leaves were transferred onto $1 \%$ phytoagar petri dishes containing $40 \mathrm{mg} / \mathrm{mL}$ benzimidazole and immediately inoculated with powdery mildew spores. Microscopic evaluation was performed $48 \mathrm{~h}$ later.

\section{Confocal microscopy}

Confocal imaging was performed using a Leica SP5-X laser-scanning microscope. Bombarded barley leaves were mounted with Perfluorodecalin (Alfa Aesar A18288) and imaging was performed with a $63 x$ water immersion lens and a numerical aperture of 1.20 . The fluorescent protein mYFP was excited at $514 \mathrm{~nm}$ and the emission collected between $527 \mathrm{~nm}$ and $586 \mathrm{~nm}$, whereas mCherry was excited at $582 \mathrm{~nm}$ and emission collected between $599 \mathrm{~nm}$ and $650 \mathrm{~nm}$. In order to restrict bleed-through and to avoid overlapping excitation-emission signals, the sequential scan mode between lines was activated. Settings for pHusion, pHluorin and CFP/YFP were according to Gjetting et al. (2012), Gao et al. (2004) and Kwaaitaal et al. (2017), respectively.

\section{Protein size and isoelectric point}

The size and pl of proteins were calculated using the Create Sequence Statistics tool of the CLC Main Workbench 7.0.2 by QIAGEN.

\section{Image processing and statistical analysis}

Planar focused images were analysed with the Leica Application Suite (LAS) Advanced Fluorescence Lite Software (Leica Microsystems $\mathrm{GmbH}$, Germany) with a clear focus on the EHM to make sure that the fluorescence in the EHMx was measured. Quantification of the signal from the protein of interest was performed with the Line Profile Tool that provides greyscale values along a linear region of interest (ROI) or the stack profile tool measuring an area of interest. The Line Profile Statistics showed the mean value for each ROI separated for the two channels (e.g. mYFP channel 1 /mCherry channel 2). For each ROI, a protein of interestvalue, normalized to an internal control (either mYFP or mCherry), was used for further analysis. Two ROls were defined for each epidermal cell with a haustorium; one in the EHMx (ROI1) and one in the plant cytosol (ROI2). By dividing the ROI1 value by the ROI2 value, a 
single value for each image was obtained, displaying the relative intensity in the EHMx. For each protein of interest, data from at least $10 \mathrm{EHMxs}$ were included in the statistical analysis (unless stated otherwise). The data are provided in Supplemental Figure S4 and Supplemental Table S3. Indirect normalization of pHusion (GFP-RFP) proteins was obtained by dividing their relative EHMx intensity by the experienced averaged relative EHMx intensity of mCherry, which is 2.86 (see above). The statistics were performed in R (https://www.r-project.org/) by using the R stats package (version 3.5.1) followed by a multiple comparison (package agricolae version 1.2-8).

\section{ACKNOWLEDGEMENTS}

We thank the Centre for Advanced Bioimaging (CAB) at the University of Copenhagen for use of their facilities. Furthermore, we thank Profs. Atsushi Miyawaki and Ralph Panstruga for sharing Yellow Cameleon constructs. We thank Independent Research Fund Denmark/Technology and Production Sciences for funding. 


\section{FIGURES}

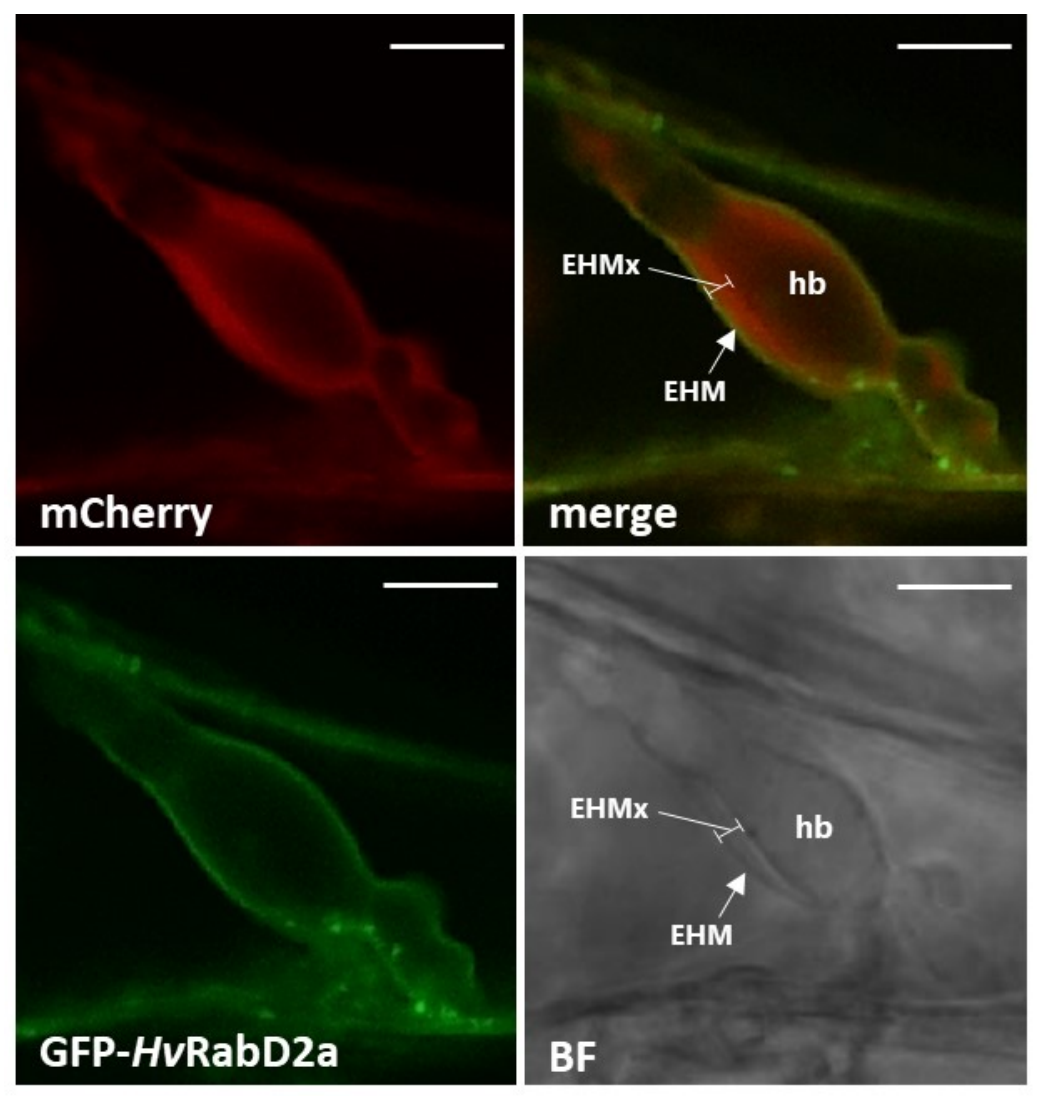

FIGURE 1 Free mCherry is translocated from the plant cytosol to the extrahaustorial matrix of $B g h$-infected barley cells. The extrahaustorial membrane is labelled with GFP-HvRabD2a. The localization was investigated $48 \mathrm{~h}$ after transient transformation and $B g h$ inoculation of barley leaf epidermal cells. hb, haustorial body; EHMx, extrahaustorial matrix; EHM, extrahaustorial membrane; BF, bright field. Images are recorded in a single plane. Scale bar, $10 \mu \mathrm{m}$. 
(a)

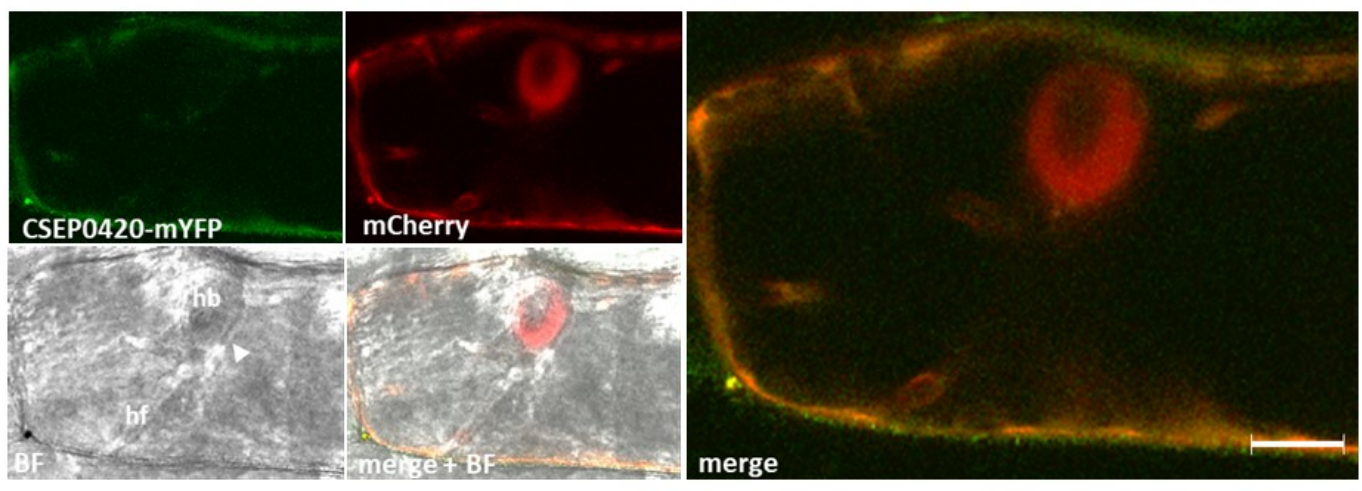

(b)

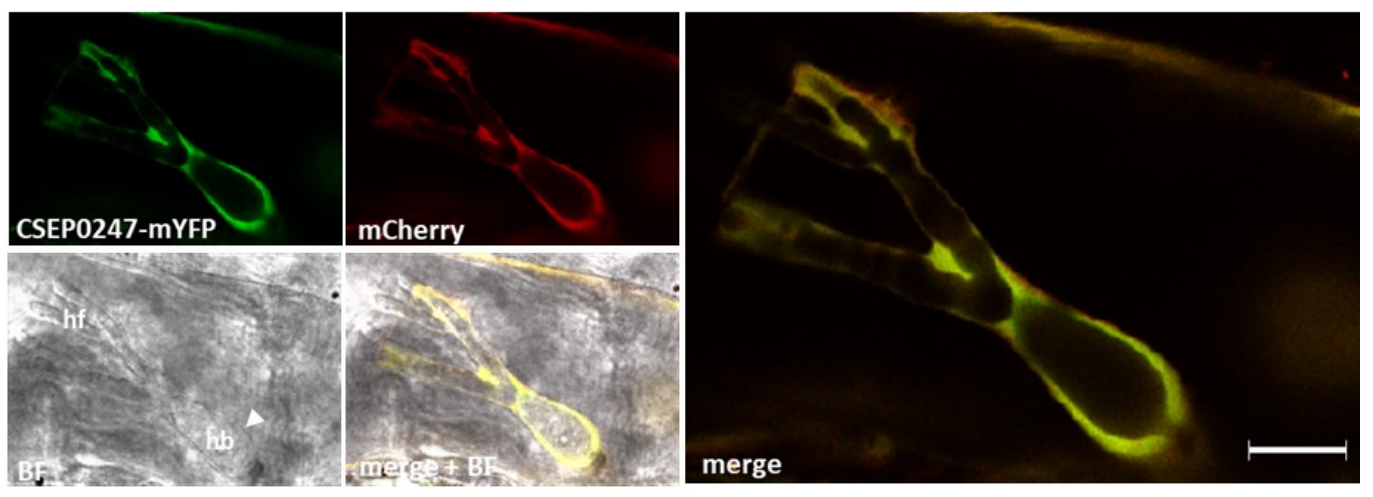

FIGURE 2 The protein sequence influences the uptake into the extrahaustorial matrix. The localization of CSEP-mYFP fusions and co-expressed mCherry was investigated $48 \mathrm{~h}$ after transient transformation and Bgh inoculation of barley leaf epidermal cells. (a) CSEPO420mYFP (59 kDa) does not localize within the extrahaustorial matrix (EHMx) as only signal from mCherry is visible. (b) CSEP0247-mYFP (72 kDa) localizes in the EHMx together with mCherry. $\mathrm{hb}$, haustorial body; hf, haustorial fingers; arrowhead, extrahaustorial matrix; BF, bright field. Images are recorded in a single plane. Scale bar, $10 \mu \mathrm{m}$. 

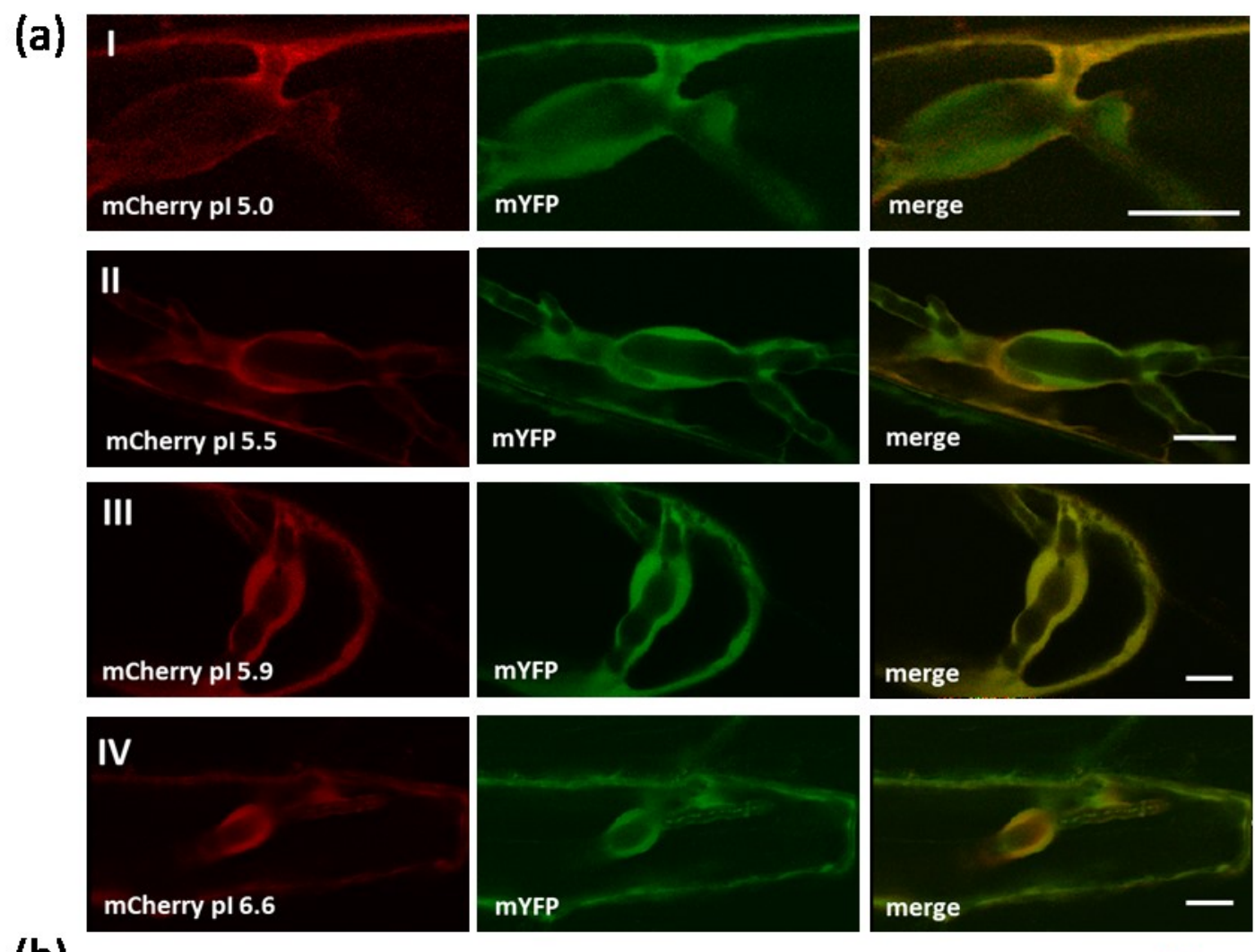

(b)
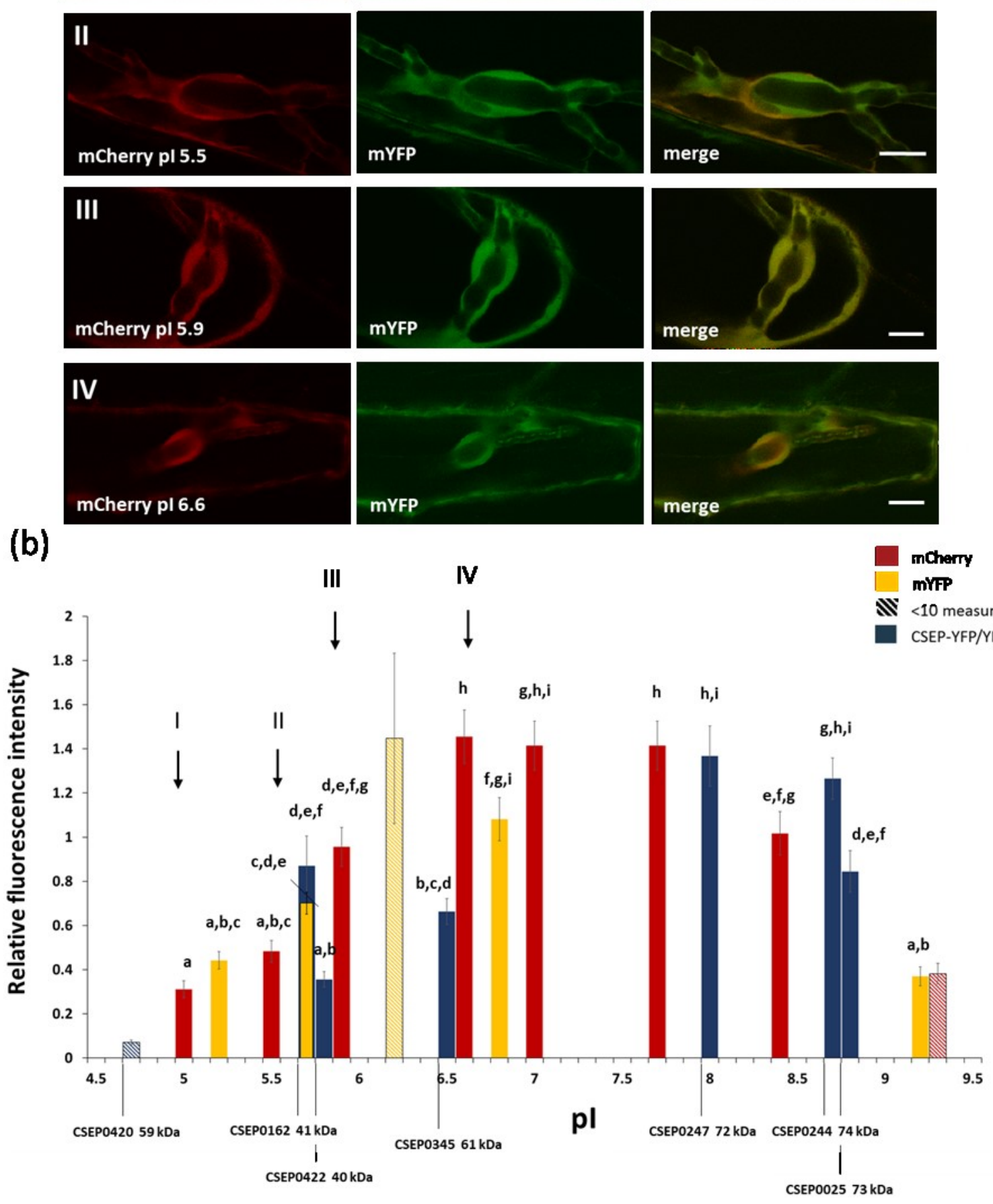

FIGURE 3 Localization of mCherry, mYFP (both $27 \mathrm{kDa}$ ) and CSEP-mYFP fusion proteins in the EHMx is influenced by their pl. The localizations were investigated $48 \mathrm{~h}$ after transient transformation and Bgh inoculation of barley leaf epidermal cells. (a) Examples of EHMx localization of mCherry, altered in its pl by addition of amino acids (see Table 2). BF, bright 
field. Images are recorded in a single plane. Scale bar, $10 \mu \mathrm{m}$. (b) Relative EHMx fluorescence of mCherry (red) and mYFP (yellow) pl-altered (see Table 2) variants was tested and normalized to unaltered mYFP and mCherry, respectively. Each data-point is based on at least 10 cells, except for the protein represented in stripes (see Table S2). Roman numbers refer to (a). CSEP-mYFP and mYFP-CSEP fusions (see Table 1) were tested as well and normalized to unaltered mCherry. The statistics were performed in R using ANOVA followed by a multiple comparison showing the least significant difference (LSD). Different letters indicate statistically significant differences $(p<0.01)$. Error bars, standard error. 
(a)

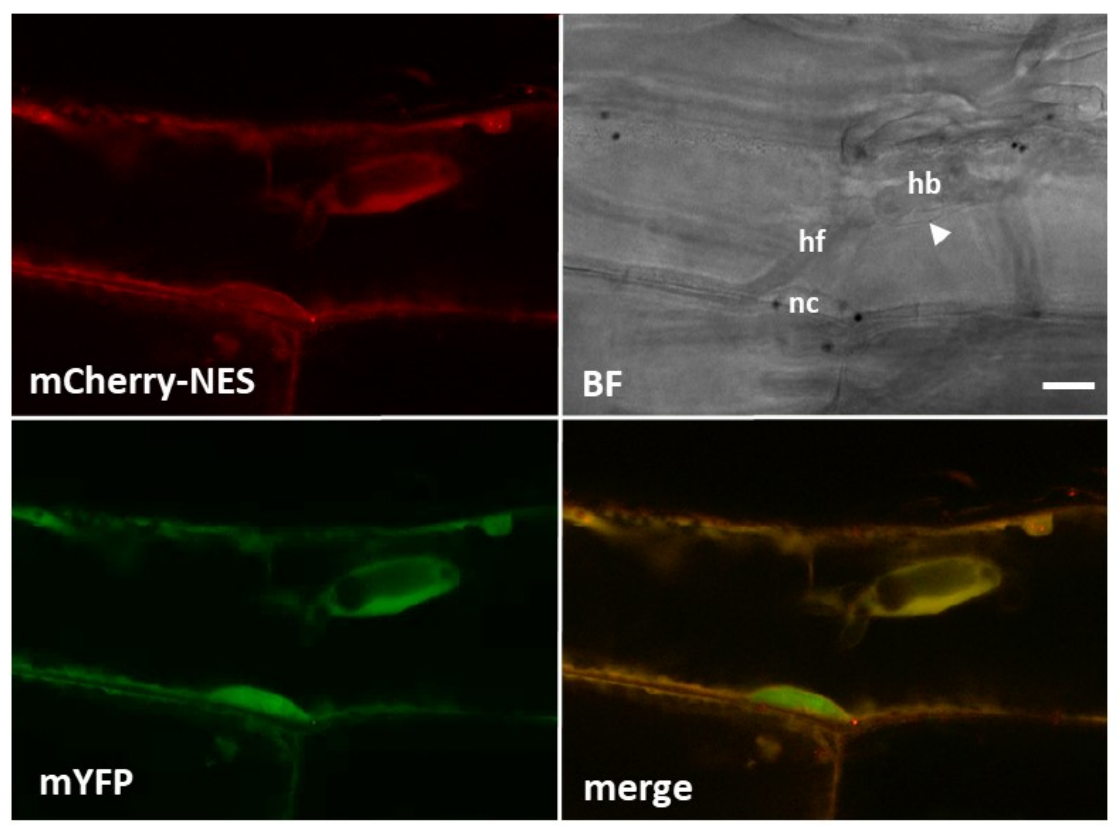

(b)

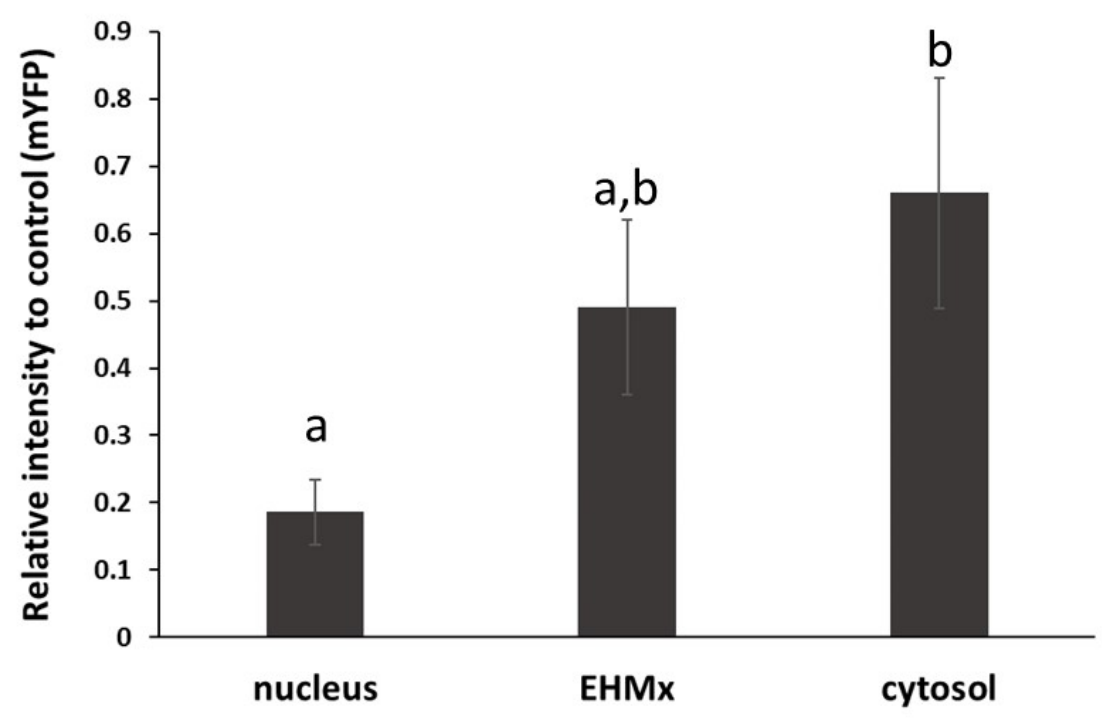

FIGURE 4 A nuclear export signal (NES) has no influence on the accumulation of mCherry in the extrahaustorial matrix. The localizations were investigated $48 \mathrm{~h}$ after transient transformation and Bgh inoculation of barley leaf epidermal cells. (a,b) Accumulation of mCherry-NES is significantly reduced, relative to MYFP, in the barley nucleus compared to the cytosol, whereas the signal in the extrahaustorial matrix (arrow) is not different. hb, haustorial body; hf, haustorial fingers; nc, nucleus; arrowhead, extrahaustorial matrix. Quantifications based on 10 images are shown. Statistics were performed in R using ANOVA followed by a multiple comparison showing the least significant difference (LSD) with $p>0.05$. Error bars, standard error. Pictures are taken in a single plane. Scale bar, $10 \mu \mathrm{m}$. 
Table 1. Visual scoring of the EHMx-localization of CSEP-mYFP and mYFP-CSEP fusion proteins suggests pl-dependency. Confocal microscopy-localizations of CSEPs (without signal peptide) fused to mYFP were investigated $48 \mathrm{~h}$ after transient transformation and $\mathrm{Bgh}$ inoculation of barley leaf epidermal cells.

\begin{tabular}{lccccccccccc}
\hline CSEP & $\mathbf{0 4 2 0}$ & $\mathbf{0 0 6 2}$ & $\mathbf{0 1 6 2}$ & $\mathbf{0 1 0 5}$ & $\mathbf{0 4 2 2}$ & $\mathbf{0 2 5 4}$ & $\mathbf{0 4 4 3}$ & $\mathbf{0 3 4 5}$ & $\mathbf{0 2 4 7}$ & $\mathbf{0 2 4 4}$ & $\mathbf{0 0 2 5}$ \\
\hline \hline $\begin{array}{l}\text { EHMx } \\
\text { localization }\end{array}$ & - & - & + & - & - & + & + & + & + & + & + \\
$\begin{array}{l}\text { Fusion } \\
\text { protein } \\
\text { size (kDa) }\end{array}$ & 59 & 44 & 45 & 41 & 41 & 39 & 38 & 61 & 72 & 74 & 73 \\
$\begin{array}{l}\text { pl of fusion } \\
\text { proteins }\end{array}$ & $\begin{array}{c}4.7 \\
\text { (CSEP- } \\
\text { mYFP) }\end{array}$ & $\begin{array}{c}4.9 \\
\text { (mYFP- } \\
\text { CSEP) }\end{array}$ & $\begin{array}{c}\text { (mYFP- } \\
\text { CSEP) }\end{array}$ & $\begin{array}{c}\text { (m) } \\
\text { CSEP- }\end{array}$ & $\begin{array}{c}\text { (CSEP- } \\
\text { mYFP) }\end{array}$ & $\begin{array}{c}\text { (mYFP- } \\
\text { CSEP) }\end{array}$ & $\begin{array}{c}\text { (CSEP- } \\
\text { mYFP) }\end{array}$ & $\begin{array}{c}\text { (CSEP- } \\
\text { mYFP) }\end{array}$ & $\begin{array}{c}\text { (CSEP- } \\
\text { mYFP) }\end{array}$ & $\begin{array}{c}8.7 \\
\text { (CSEP- } \\
\text { mYFP) }\end{array}$ & $\begin{array}{c}8.8 \\
\text { (CSEP- } \\
\text { mYFP) }\end{array}$ \\
\hline
\end{tabular}


Table 2. Addition of amino acids at the C-terminus alters the pl of mCherry and mYFP proteins.

\begin{tabular}{lccccccccc}
\hline & 12 Asp & $\begin{array}{c}\text { 8 Asp } \\
\text { 4 Lys }\end{array}$ & 12 Ala & $\begin{array}{c}\text { 4 Asp } \\
\text { 8 Lys }\end{array}$ & $\begin{array}{c}\text { 5 Lys } \\
\text { 7 Ala }\end{array}$ & $\begin{array}{c}\text { 6 Ala } \\
\text { 6 Lys }\end{array}$ & $\begin{array}{c}\text { 7 Lys Ala } \\
\text { 5 }\end{array}$ & $\begin{array}{c}\text { 12 } \\
\text { Lys }\end{array}$ & $\begin{array}{c}\text { Unal- } \\
\text { tered }\end{array}$ \\
\hline \hline mCherry pl & 5.03 & 5.47 & 5.85 & 6.62 & 6.96 & 7.70 & 8.41 & 9.25 & 5.85 \\
mYFP pl & 5.16 & 5.73 & 6.16 & 6.84 & - & - & - & 9.17 & 6.16 \\
\hline
\end{tabular}


Table 3. Several double-fluorescent proteins localize poorly to the extrahaustorial matrix. Confocal microscopy was used to investigate accumulation $48 \mathrm{~h}$ after transient transformation and Bgh inoculation of barley leaf epidermal cells. Yellow Cameleon and CFP-YFP were normalized using co-expressed mCherry. For pHusion, no internal control was possible due to technical limitations. Therefore, indirect normalization using an overall relative EHMx intensity of mCherry (2.86) was employed.

\begin{tabular}{lccccc}
\hline Construct & pl & $\begin{array}{c}\text { Size } \\
(\mathbf{k D a})\end{array}$ & $\begin{array}{c}\text { Rel. intensity in EHMx } \\
\text { (no. of cells) }\end{array}$ & $\begin{array}{c}\text { Normalized directly } \\
\text { (d) or indirectly (i) }\end{array}$ & Reference \\
\hline \hline Yellow Cameleon (YC3.6) & 5.5 & 73 & $0.28(7)$ & $0.13(\mathrm{~d})$ & Nagai et al., 2004 \\
pHusion & 5.9 & 52 & $0.49(7)$ & $0.17(\mathrm{i})$ & Gjetting et al., 2012 \\
pHusion pl 6.2 4D8K & 6.2 & 52 & $0.37(6)$ & $0.13(\mathrm{i})$ & this work \\
pHusion pl 6.5 7K5A & 6.5 & 52 & $0.33(2)$ & $0.11(\mathrm{i})$ & this work \\
CFP-YFP & 6 & 52 & $0.40(7)$ & $0.13(\mathrm{~d})$ & Bethke et al., 2009 \\
\hline
\end{tabular}




\section{References}

Aguilar, G. B., Pedersen, C., \& Thordal-Christensen, H. (2016). Identification of eight effector candidate genes involved in early aggressiveness of the barley powdery mildew fungus. Plant Pathol., 65, 953-958. https://doi.org/10.1111/ppa.12476

Ahmed, A. A., Pedersen, C., Schultz-Larsen, T., Kwaaitaal, M., Jørgensen, H. J. L., \& ThordalChristensen, H. (2015). The barley powdery mildew candidate secreted effector protein CSEP0105 inhibits the chaperone activity of a small heat shock protein. Plant Physiol., 168, 321-333. https://doi.org/10.1104/pp.15.00278

Bethke, G., Unthan, T., Uhrig, J. F., Poschl, Y., Gust, A. A., Scheel, D., \& Lee, J. (2009). Flg22 regulates the release of an ethylene response factor substrate from MAP kinase 6 in Arabidopsis thaliana via ethylene signaling. PNAS, 106(19), 8067-8072. https://doi.org/10.1073/pnas.0810206106

Collins, N. C., Thordal-Christensen, H., Lipka, V., Bau, S., Kombrink, E., Qiu, J.-L. L., ... SchulzeLefert, P. (2003). SNARE-protein-mediated disease resistance at the plant cell wall. Nature, 425(6961), 973-977. https://doi.org/10.1038/nature02076

Emmanouilidis, L., Gopalswamy, M., Passon, D. M., Wilmanns, M., \& Sattler, M. (2016). Structural biology of the import pathways of peroxisomal matrix proteins. Biochim Biophys Acta, 1863, 804-813. https://doi.org/10.1016/j.bbamcr.2015.09.034

Freitas, N., \& Cunha, C. (2009). Mechanisms and signals for the nuclear import of proteins. Current Genomics, 10(8), 550-557. https://doi.org/10.2174/138920209789503941

Gao, D., Knight, M. R., Trewavas, A. J., Sattelmacher, B., \& Plieth, C. (2004). Self-Reporting arabidopsis expressing $\mathrm{pH}$ and $\left[\mathrm{Ca}^{2+}\right]$ indicators unveil ion dynamics in the cytoplasm and in the apoplast under abiotic stress. Plant Physiol., 134(3), 898-908. https://doi.org/10.1104/pp.103.032508

Gjetting, K. S. K., Ytting, C. K., Schulz, A., \& Fuglsang, A. T. (2012). Live imaging of intra-and extracellular $\mathrm{pH}$ in plants using pHusion, a novel genetically encoded biosensor. J. Exp. Bot., 63(8), 3207-3218. https://doi.org/10.1093/jxb/ers040

Haasen, D., Köhler, C., Neuhaus, G., \& Merkle, T. (1999). Nuclear export of proteins in plants: AtXPO1 is the export receptor for leucine-rich nuclear export signals in Arabidopsis thaliana. Plant J., 20(6), 695-705. https://doi.org/10.1046/j.1365-313X.1999.00644.x

Kunze, M., \& Berger, J. (2015). The similarity between N-terminal targeting signals for protein import into different organelles and its evolutionary relevance. Front Physiol., 6(259), 127. https://doi.org/10.3389/fphys.2015.00259

Kwaaitaal, M., Keinath, N. F., Pajonk, S., Biskup, C., \& Panstruga, R. (2010). Combined bimolecular fluorescence complementation and förster resonance energy transfer reveals ternary SNARE complex formation in living plant cells. Plant Physiol., 152(3), 1135-1147. https://doi.org/10.1104/pp.109.151142

Kwaaitaal, Mark, Nielsen, M. E., Böhlenius, H., \& Thordal-Christensen, H. (2017). The plant membrane surrounding powdery mildew haustoria shares properties with the endoplasmic reticulum membrane. J. Exp. Bot., 68(21-22), 5731-5743. 
https://doi.org/10.1093/jxb/erx403

Lu, X., Kracher, B., Saur, I. M. L., Bauer, S., Ellwood, S. R., Wise, R., ... Schulze-Lefert, P. (2016). Allelic barley MLA immune receptors recognize sequence-unrelated avirulence effectors of the powdery mildew pathogen. PNAS, 113(42), E6486-E6495. https://doi.org/10.1073/pnas.1612947113

Markert, Y., Koditz, J., Ulbrich-Hofmann, R., \& Arnold, U. (2003). Proline versus charge concept for protein stabilization against proteolytic attack. Protein Eng., 16(12), 1041-1046. https://doi.org/10.1093/protein/gzg136

Miesenböck, G., De Angelis, D. A., \& Rothman, J. E. (1998). Visualizing secretion and synaptic transmission with $\mathrm{pH}$-sensitive green fluorescent proteins. Nature, 394(6689), 192-195. https://doi.org/10.1038/28190

Nagai, T., Yamada, S., Tominaga, T., Ichikawa, M., \& Miyawaki, A. (2004). Expanded dynamic range of fluorescent indicators for $\mathrm{Ca}^{2+}$ by circularly permuted yellow fluorescent proteins, 101(29), 10554-10559.

Pedersen, C., Ver Loren van Themaat, E., McGuffin, L. J., Abbott, J. C., Burgis, T. A., Barton, G., ... Spanu, P. D. (2012). Structure and evolution of barley powdery mildew effector candidates. BMC Genomics, 13(1), 694. https://doi.org/10.1186/1471-2164-13-694

Pennington, H. G., Gheorghe, D. M., Damerum, A., Pliego, C., Spanu, P. D., Cramer, R., \& Bindschedler, L. V. (2016). Interactions between the powdery mildew effector BEC1054 and barley proteins identify candidate host targets. J. Proteome Res., 15(3), 826-839. https://doi.org/10.1021/acs.jproteome.5b00732

Rasco-Gaunt, S., Riley, A., Barcelo, P., \& Lazzeri, P. A. (1999). Analysis of particle bombardment parameters to optimise DNA delivery into wheat tissues. Plant Cell Rep., 19(2), 118-127. https://doi.org/10.1007/s002990050721

Scott, P. M. (2013). Transgenic Maize: Methods and Protocols. In Methods in Molecular Biology (Vol. 53, pp. 1689-1699). https://doi.org/10.1017/СBO9781107415324.004

Sivamani, E., Delong, R. K., \& Qu, R. (2009). Protamine-mediated DNA coating remarkably improves bombardment transformation efficiency in plant cells. Plant Cell Rep., 28(2), 213-221. https://doi.org/10.1007/s00299-008-0636-4

Soleja, N., Manzoor, O., Khan, I., Ahmad, A., \& Mohsin, M. (2018). Role of green fluorescent proteins and their variants in development of FRET-based sensors. J. Biosci, 43(4), 763784. https://doi.org/10.1007/s12038-018-9783-0

Testut, J. F., Callow, J. A., \& Green, J. R. (1999). Evidence that PSI-D, a chloroplast photosystem I protein, is in haustoria of the powdery mildew fungus Erysiphe pisi. Physiol. Mol. Plant Pathol., 55(6), 349-358. https://doi.org/10.1006/pmpp.1999.0238

Weiller, G. F., Caraux, G., \& Sylvester, N. (2004). The modal distribution of protein isoelectric points reflects amino acid properties rather than sequence evolution. Proteomics, 4(4), 943-949. https://doi.org/10.1002/pmic.200200648

Zhang, W.-J., Hanisch, S., Kwaaitaal, M., Pedersen, C., \& Thordal-Christensen, H. (2013). A component of the Sec61 ER protein transporting pore is required for plant susceptibility $\begin{array}{lllll}\text { to powdery mildew. Front Plant } & \text { 4(May), }\end{array}$ 
https://doi.org/10.3389/fpls.2013.00127 


\section{SUPPLEMENTALS}

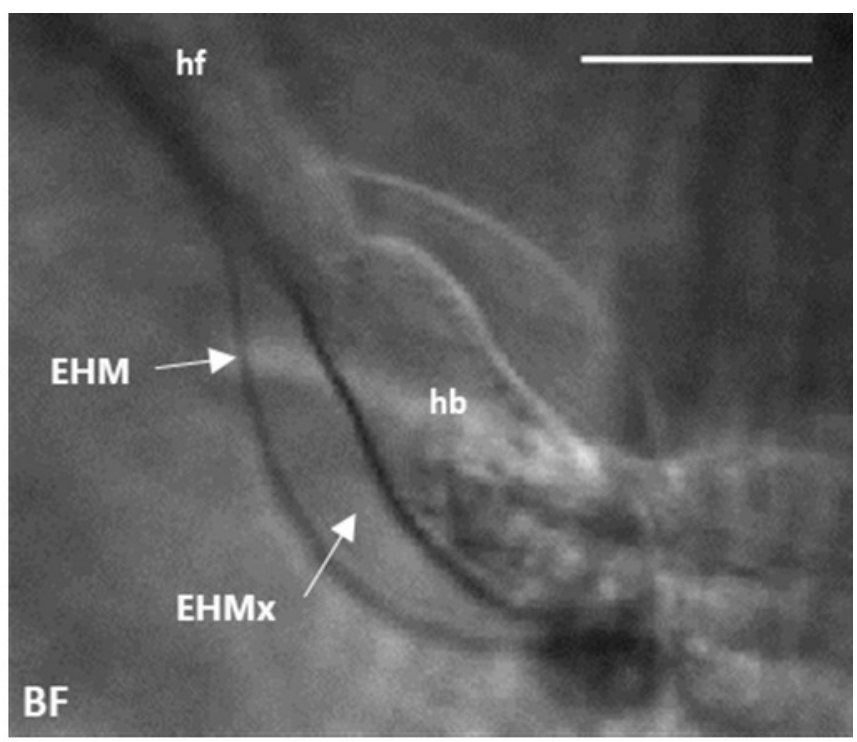

SUPPLEMENTAL FIGURE S1 The extrahaustorial matrix (EHMx) is a compartment surrounding the haustorial body ( $\mathrm{hb}$ ) deliminated by the extrahaustorial membrane (EHM). Bright field (BF) image of a Bgh-haustorium 48 hours after inoculation of barley plants. hf, haustorial fingers; $\mathrm{BF}$, bright field. Picture is taken in a single plane. Scale bar, $10 \mu \mathrm{m}$. 


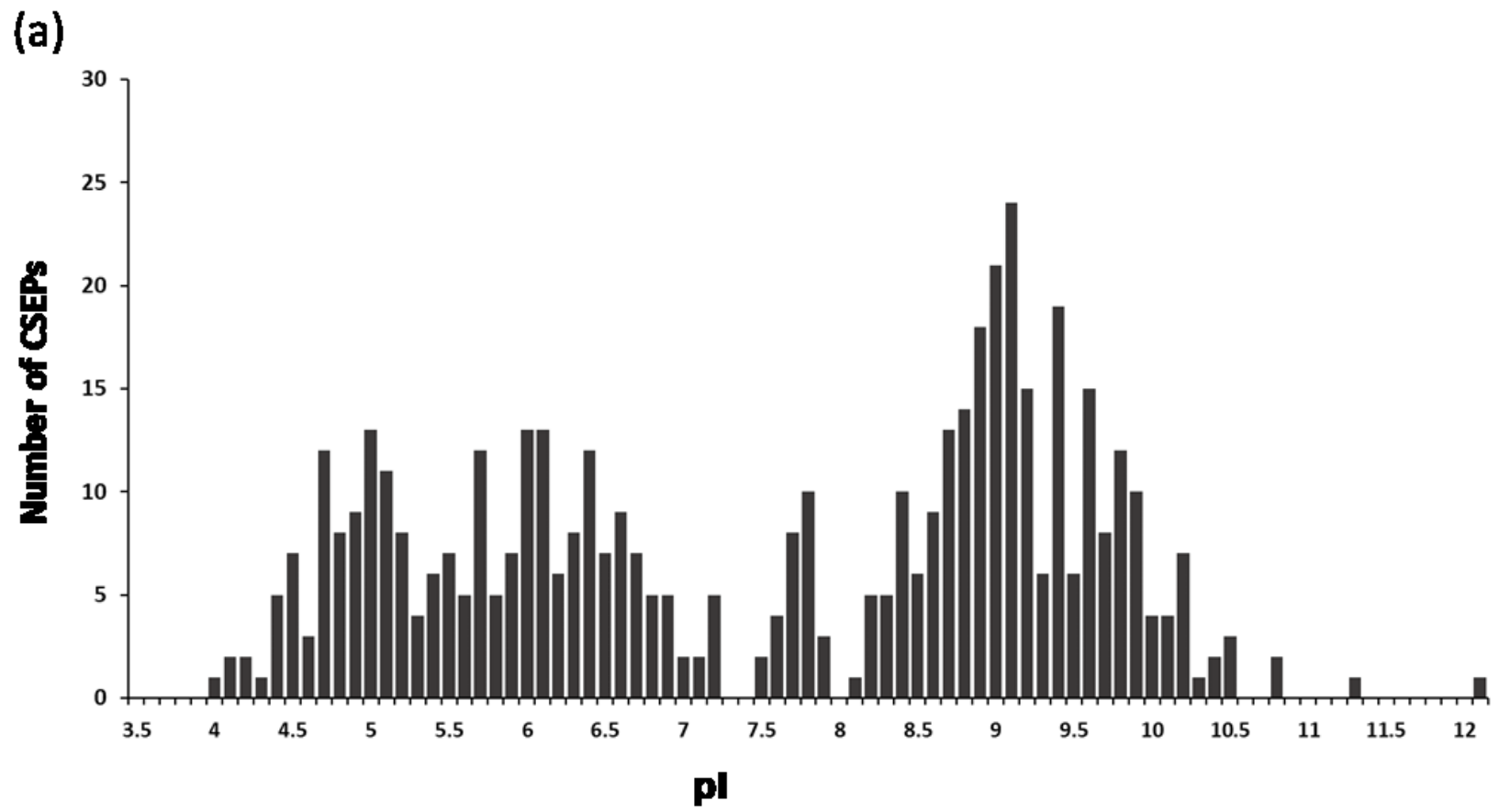

(b)

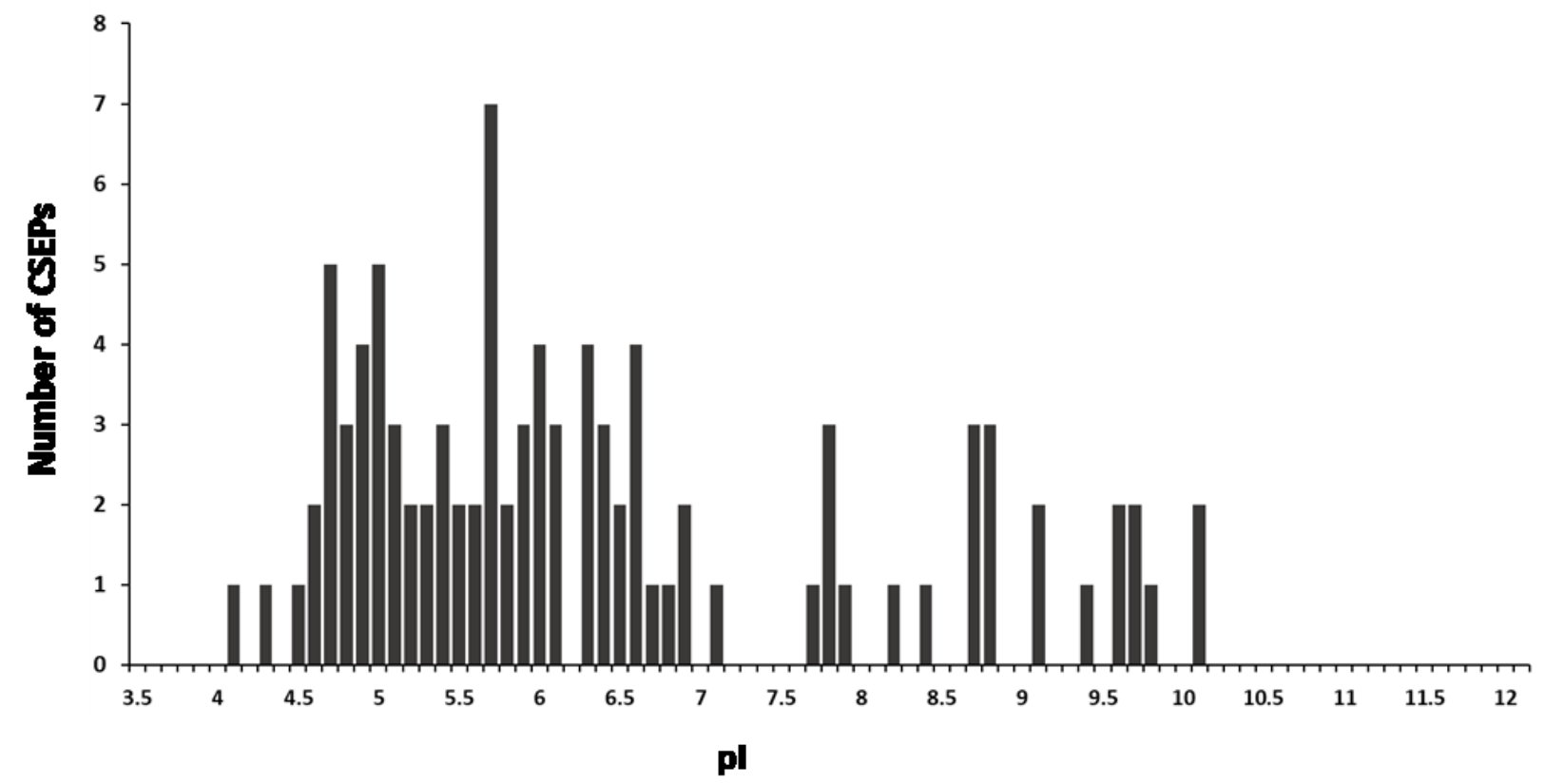

SUPPLEMENTAL FIGURE S2 Number of candidate secreted effector proteins (CSEPs) with indicated isoelectric points (pl's). (a) All 491 Bgh CSEPs from Pedersen et al. (2012). (b) 96 Bgh CSEPs highly expressed in the haustorium (Pedersen et al., 2012). 


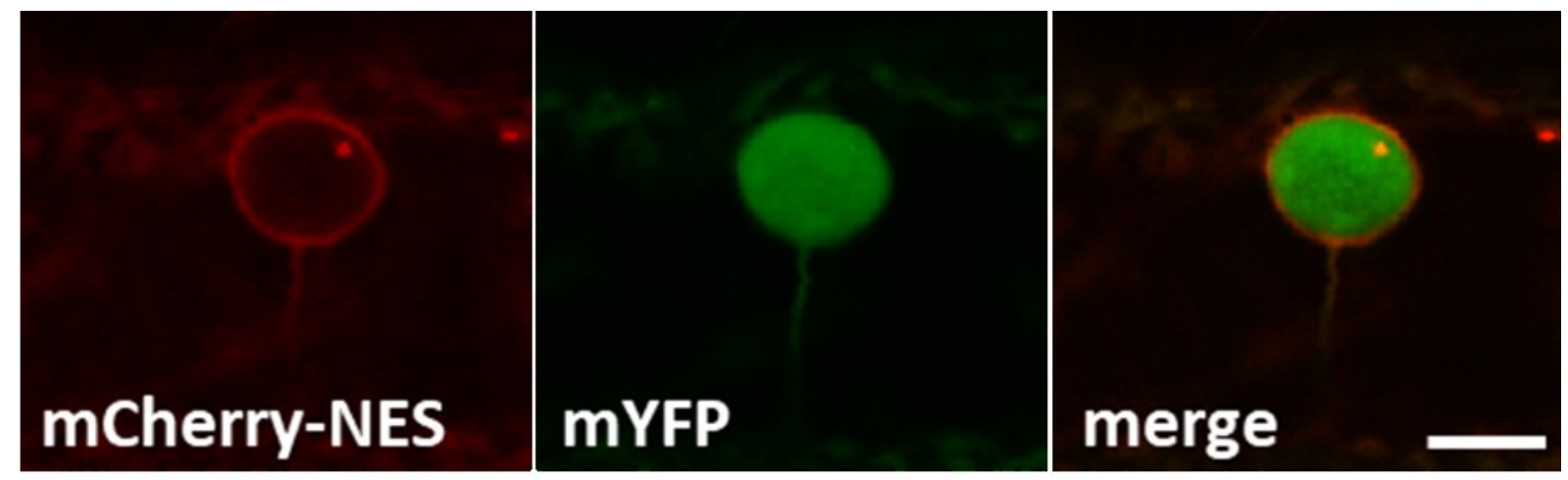

SUPPLEMENTAL FIGURE S3 A nuclear export signal (NES) efficiently excludes mCherry from the nucleus. The localizations were investigated $48 \mathrm{~h}$ after transient transformation of barley leaf epidermal cells. Scale bar, $10 \mu \mathrm{m}$. 
(a)

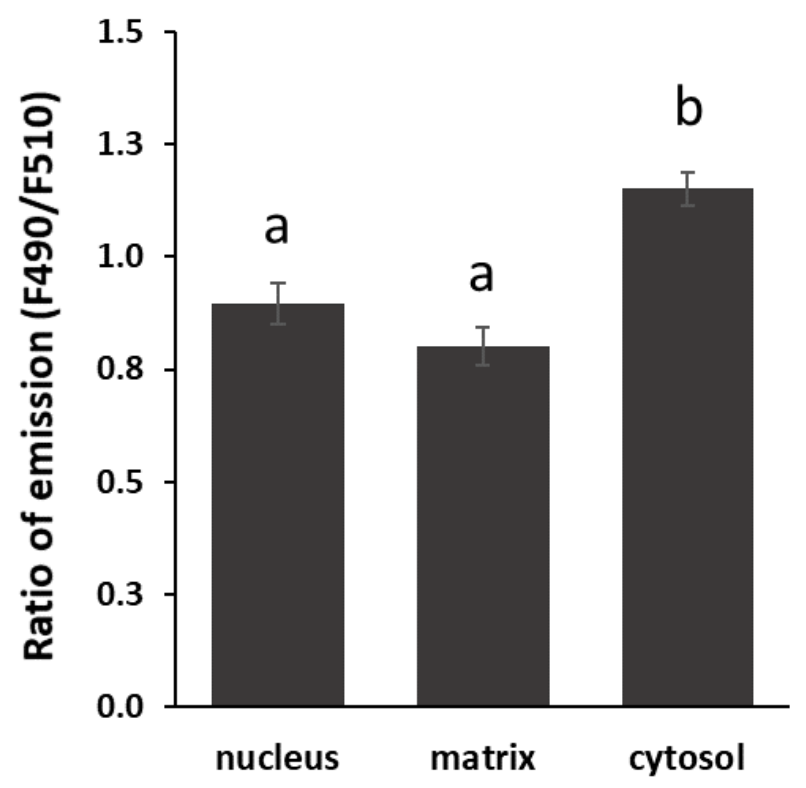

(b)

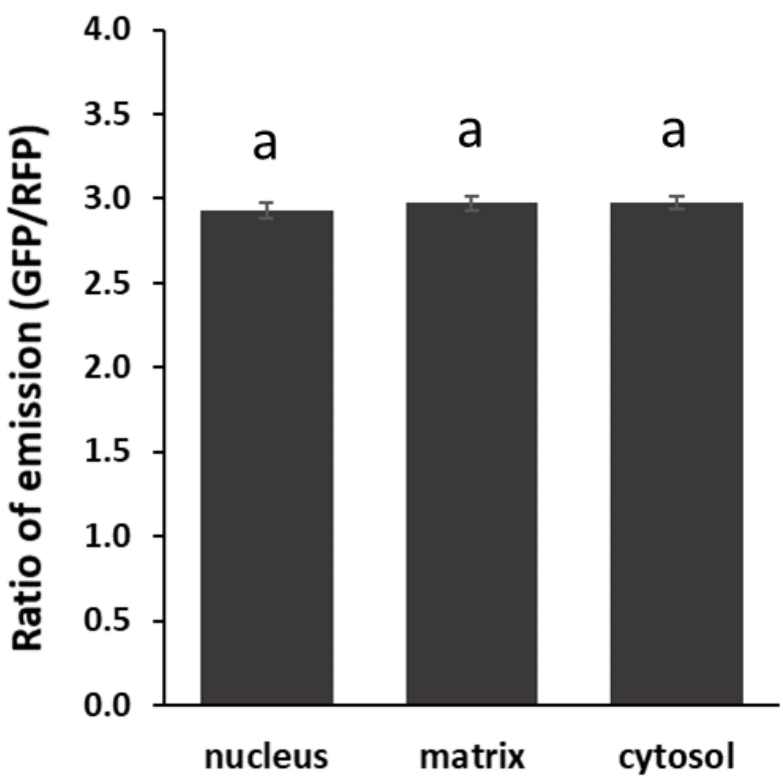

SUPPLEMENTAL FIGURE S4 Little differentiation in $\mathrm{pH}$ between cytosol and extrahaustorial matrix. Fluorescence emission ratios of $\mathrm{pH}$ sensors in the nucleus, matrix and cytosol investigated $48 \mathrm{~h}$ after transient transformation and $B g h$ inoculation of barley leaf epidermal cells. (a) F490/F510 emission ratio of pHluorin (mean of data from 15 cells). (b) GFP/RFP emission ration of pHusion (mean of data from 10 cells, except for the nucleus, where only four measurements were obtained). An ANOVA was performed in R followed by a multiple comparison showing the least significant difference (LSD) with $p>0.05$. In both cases the stack profile tool was used. Error bars, standard error. 
SUPPLEMENTAL TABLE S1. Primer sequences used for PCR reactions.

\begin{tabular}{|c|c|c|}
\hline name & forward & reverse \\
\hline mCherry pl 5.03/mYFP pl 5.16 & CACCATGGTGAGCAAGGGCGAG & TCAATCGTCATCGTCATCGTCATCATCGTCGTCATCATCCTTGTACAGCTCGTCCAT \\
\hline mCherry pl 5.47/mYFP pl 5.73 & CACCATGGTGAGCAAGGGCGAG & TCACTTCTTCTTTTTATCATCGTCGTCATCATCGTCGTCCTTGTACAGCTCGTCCAT \\
\hline mCherry pl 5.85/mYFP pl 6.16 & CACCATGGTGAGCAAGGGCGAG & TCACGCCGCGGCGGCCGCCGCGGCAGCCGCGGCAGCAGCCTTGTACAGCTCGTCCAT \\
\hline mCherry pl 6.62/mYFP 6.84 & CACCATGGTGAGCAAGGGCGAG & TCACTTCTTCTTCTTCTTCTTTTTCTTGTCGTCATCGTCCTTGTACAGCTCGTCCAT \\
\hline mCherry pl 6.96 & CACCATGGTGAGCAAGGGCGAG & TCACGCCGCGGCGGCCGCTTTCTTCTTCTTCTTCTTTTTCTTGTACAGCTCGTCCAT \\
\hline mCherry pl 7.7 & CACCATGGTGAGCAAGGGCGAG & TCACGCCGCGGCGGCCGCCGCCTTCTTCTTCTTCTTTTTTCTTGTACAGCTCGTCCAT \\
\hline mCherry pl 8.41 & CACCATGGTGAGCAAGGGCGAG & TCACGCCGCGGCGGCCGCCGCGGCCTTCTTCTTCTTTTTTCTTGTACAGCTCGTCCAT \\
\hline mCherry pl 9.25/mYFP 9.17 & CACCATGGTGAGCAAGGGCGAG & TCACTTCTTTTTTTTCTTCTTCTTCTTCTTCTTCTTTTTCTTGTACAGCTCGTCCAT \\
\hline mCherry_NES & CACCATGGTGAGCAAGGGCGAG & TCACTCCACGGTCAGCTTCTCCAGCAGGCCGGCGGTCTTCTTGTACAGCTCGTCCAT \\
\hline CSEP0420 & CACCATGGCACCTCTGTCACCTTTAAAGTC & CTCGGCTTTCTTGTCATCTG \\
\hline CSEP0062 & CACCAAAAGCAACTACGTGTGCCC & ATGTGTTTTGGGTTTTCCCTCG \\
\hline CSEP0422 & CACCATGTTTGTTAAGAATTACGTACCATACG & AAATTGGACGGTTCCTCTTC \\
\hline CSEP0443 & CACCATGGCTAAATATTATACATGTGGCG & TTTACAATCCACAGATACGTT \\
\hline CSEP0345 & CACCATGTCGAAGCTGTTCCATC & GCCCAACCAACCTTTTGC \\
\hline CSEP0247 & CACCATGACCAATGTTCCATACTC & GGATTCTGTGACTTGACC \\
\hline CSEP0244 & CACCATGGCAAATATCCCATACTCG & AGAATCGGTGGCTGGTCG \\
\hline CSEP0025 & CACCATGGTGAATATACCATACTCGG & GAGCTGTATGACTGAGCT \\
\hline pHusion pl 6.2 & CACCATGGCCTCCTCCGAGGAC & TCACTTCTTCTTCTTCTTCTTTTTCTTGTCGTCATCGTCCTTGTACAGCTCGTCCAT \\
\hline pHusion pl 6.5 & CACCATGGCCTCCTCCGAGGAC & TCACGCCGCGGCGGCCGCCGCGGCCTTCTTCTTCTTTTTTCTTGTACAGCTCGTCCAT \\
\hline GWYC36 & $\begin{array}{l}\text { GGGGACAAGTTTGTACAAAAAAGCAGGCTTAGCGGCCG } \\
\text { CCACCATGGTG }\end{array}$ & GGGGACCACTTTGTACAAGAAAGCTGGGTCATATCTGCAGAATTCTTACTC \\
\hline
\end{tabular}


SUPPLEMENTAL TABLE S2. Raw data of localization study in Figure 3.

\begin{tabular}{lcccccc}
\hline & $\mathbf{p l}^{\mathbf{1}}$ & No. of images & No. of exp. & Relative intensity & SD $^{\mathbf{2}}$ & SE $^{3}$ \\
\hline mCherry & 5.03 & 11 & 4 & 0.311 & 0.126 & 0.038 \\
mYFP & 5.16 & 13 & 3 & 0.442 & 0.136 & 0.039 \\
mCherry & 5.47 & 18 & 3 & 0.483 & 0.209 & 0.049 \\
mYFP & 5.73 & 13 & 2 & 0.701 & 0.172 & 0.050 \\
mCherry & 5.85 & 12 & 2 & 0.957 & 0.304 & 0.088 \\
mYFP & 6.16 & 5 & 5 & 1.447 & 0.862 & 0.386 \\
mCherry & 6.62 & 13 & 4 & 1.455 & 0.435 & 0.121 \\
mYFP & 6.84 & 10 & 5 & 1.082 & 0.309 & 0.098 \\
mCherry & 6.96 & 20 & 3 & 1.229 & 0.303 & 0.068 \\
mCherry & 7.7 & 15 & 2 & 1.415 & 0.428 & 0.111 \\
mCherry & 8.41 & 12 & 2 & 1.017 & 0.341 & 0.098 \\
mYFP & 9.17 & 12 & 3 & 0.370 & 0.149 & 0.043 \\
mCherry & 9.25 & 5 & 2 & 0.382 & 0.104 & 0.046 \\
\hline
\end{tabular}

${ }^{1}$ Calculated isoelectric point.

${ }^{2}$ Standard deviation.

${ }^{3}$ Standard error. 
SUPPLEMENTAL TABLE S3 Raw data of localization study in Supplemental Figure S4.

\begin{tabular}{|c|c|c|c|c|c|c|}
\hline Name & & No. of images & No. of exp. & Relative intensity & $S D^{1}$ & $S E^{2}$ \\
\hline \multicolumn{7}{|c|}{ mCherry-NES } \\
\hline & - $\quad$ Nucleus & \multirow{3}{*}{11} & \multirow{3}{*}{2} & 0.175 & 0.153 & 0.048 \\
\hline & - $\quad \mathrm{EHMx}$ & & & 0.581 & 0.547 & 0.173 \\
\hline & - Cytosol & & & 0.660 & 0.542 & 0.171 \\
\hline \multicolumn{7}{|c|}{ pHluorin } \\
\hline & - $\quad$ Nucleus & \multirow{3}{*}{15} & \multirow{3}{*}{3} & 0.895 & 0.178 & 0.0460 \\
\hline & - $\quad E H M x$ & & & 0.802 & 0.162 & 0.0418 \\
\hline & - $\quad$ Cytosol & & & 1.151 & 0.144 & 0.0374 \\
\hline \multicolumn{7}{|c|}{ pHusion } \\
\hline & - $\quad$ Nucleus & 4 & 2 & 2.929 & 0.5273 & 0.264 \\
\hline & - $\quad E H M x$ & 10 & 3 & 2.975 & 1.31 & 0.414 \\
\hline & - Cytosol & 10 & 3 & 2.980 & 1.123 & 0.355 \\
\hline
\end{tabular}

${ }^{1}$ Standard deviation.

${ }^{2}$ Standard error. 